\title{
Effect of Mulligan Bent Leg Raise Technique on Hamestring Shortening Following Lower Limb Burn
}

\author{
HISHAM M.O. ABO ELSOUD, M.Sc.*; HANY M. ELGOHARY, Ph.D.*; AMR A.M. ABOUZID, M.D.** and \\ INTSAR S. WAKED, Ph.D.*
}

The Department of Physical Therapy for Surgery*, Faculty of Physical Therapy, Cairo University and Department of Surgical Oncology**, Faculty of Medicine, Mansoura University

\begin{abstract}
Background: Globally, burns are a serious public health problem and Knee post burn scar flexion contractures, makes up $22 \%$ of large joint contractures.

Stretching is effective method to improve muscle length and mulligan bent leg raise is a modification of straight leg raise which increase hamstring flexibility and length.

Aim of Study: This study has been conducted to evaluate the effect of the mulligan bent leg raise technique on elongation of hamstring muscle and the reflection of that on some quantitative gait parameters and the range of motion (ROM) of knee extension.

Patients and Methods: Thirty male patients between 3050 years were participated in this study, with a second-degree posterior leg burn and a total body surface area of $15-20 \%$. They were divided randomly into two equal groups, study group (A), 15 patients received mulligan bent leg raise technique plus the traditional physical therapy program and control group (B), 15 patients received only the same traditional physical therapy program. Measurements were recorded before treatment and after third, sixth and eighth week of treatment (session for 30 minutes, 5 days/week for a total period of 2 months). A 16-meter walkway and tape measure were used to measure the quantitative gait parameters, while manual goniometer was used for measuring ROM of knee flexion. patients were examined at the outpatient clinic of Cairo University during the period from December 2020 to February 2021.
\end{abstract}

Results: There was a significant decrease in knee flexion ROM and step width and a significant increase in step length and stride length of the study group (group A) at post I, post II and post III compared with that of the control group (group B) $(p<0.001)$.

Conclusion: It is concluded that the mulligan bent leg raise technique is effective in elongating the hamstring muscle as reflected by the improved gait parameters as well as the ROM of knee extension.

Key Words: Mulligan bent leg raise - Shortening - Hamstring - Burn.

Correspondence to: Dr. Hisham M.O. Abo Elsoud, The Department of Physical Therapy for Surgery, Faculty of Physical Therapy, Cairo University

\section{Introduction}

SKIN is the largest organ in the human body, burn injury causes destruction and disturbance of the normal physiological functions of the skin [1-3]

The most important goal of burn rehabilitation protocol is to help patients to return to their normal life and return back into society as soon as possible $[2,3]$

Patients with lower limb burns, often take a lot of time and effort to regain their lost walking proficiency, contracted gastrocnemius-soleus muscles result in temporary versus a permanent gait and postural deformities depends on the patient's compliance with an overall rehabilitation program established in consultation with the physical therapist $[4,5]$.

Flexibility is the ability to move a single joint or series of joints through an unrestricted pain free range of motion (ROM). It is dependent upon the extensibility of muscle which allows muscle that crosses a joint to relax, lengthen and yield to a stretch force [6].

Posterior femoral muscles include Biceps femoris, Semitendinosus, Semimembranosus collectively termed as Hamstrings, which crosses hip and knee joints integrating co-axial extension with genu flexion. Functioning as a unit, the hamstrings are responsible for flexion of knee joint, as well as extension of hip through the movement of the thigh in a reverse direction [7]

There are many approaches for lengthening the shorted muscles as gait training, passive and active stretch, in general, stretching exercises are the most important modality in elongating the patho- 
logically shortened soft tissue structures and thereby increasing the range of motion (ROM) [8,9].

Achieving adequate range of motion following burn is a major concern for patients and physicians. Degrees of ROM lost after burn can result in increased patient suffer during ADL activities, higher healthcare costs and increases hospital stay time [10].

Limitation of ROM occurs during the early post-burn injury period resulting from edema, pain, improper positioning, muscle shortening and even contracture, scar contracture or tendon injury [11]

A desire to improve quality of life post-burn injury has led to the development of multimodal approaches to post-burn injury [12]

So, Mulligan Bent Leg Raise Technique can be more effective in improving ROM post-burn and may help to improve long-term quality of life in patients with limited knee range of motion [13]

The need of this study developed from the lack in the quantitative knowledge and information in the published studies about the effect of Mulligan Bent Leg Raise Technique in improving Knee extension ROM as well as gait parameters following burn injury.

\section{Material and Methods}

\section{Population:}

40 participants were screened. A total of 30 of them met the inclusion criteria and accepted to participate and join the study. patients were examined at the outpatient clinic of Cairo University during the period from December 2020 to February 2021.

\section{Inclusion criteria:}

Thirty male patients ranging in age from 30 to 50 years participated in this study, they were diagnosed as healed second degree posterior leg burn and the total body surface area of burn was from 15 to $20 \%$.

Patients were randomly divided into two groups of equal number, the bent leg raise (BLR) group (study group), that received the mulligan bent leg raise technique plus the traditional physical therapy program for burn injury in the form of range of motion exercises for the affected knee joint in addition to self-stretching exercises for the ipsilateral hamstring muscles. While the second group was the control group that received the same traditional physical therapy program.

\section{Exclusion criteria:}

- Any traumatic or infectious condition that involve the affected lower limb.

- Pathologies and deformities related to knee and hip joints.

- Recent knee surgery.

- Neurological causes of impaired knee range of motion

- Sever Cardiac diseases.

- Neurological or musculoskeletal complications affecting the lower limb.

- Patients with any dysfunction or associated injuries or any pathological conditions which may affect the results of the study.

- Patients who had cardiac abnormalities or cardiac pacemakers.

- Patients who had previous surgical procedures which may affect the results of the study.

\section{The measuring equipment:}

The measuring tools in this study were the quantitative gait analysis tools, which were a tape measure to record the distance variables, a 16meter walkway, that was fabricated from a plastic material (the 5-meter areas on each end of the walkway were used for warming up and slowing down before and after measurement respectively, while the middle 6-meter area was the measurement area (Figs. 1,2) and a marking pen. Then we measured step length, step width and stride length Plus, a standard goniometer to measure ROM of knee flexion $[\mathbf{1 4 , 1 5}]$.

Measurements were obtained before starting the treatment protocol, after one week of treatment as post I, after one month of treatment as Post II, and at the end of the treatment protocol after two months as post III.

\section{Therapeutic procedures:}

Group A:

This group received Mulligan Bent Leg Raise Technique and traditional physical therapy program in the form of (active knee range of motion exercise and self-stretching of hamstring) five times a week for two months of treatment.

\section{Mulligan bent leg raise technique:}

Patient's position:

The patient was positioned in a supine lying position with the affected knee rested on the therapist shoulder so as hip and knee were bent at 90 and 90 degrees. 


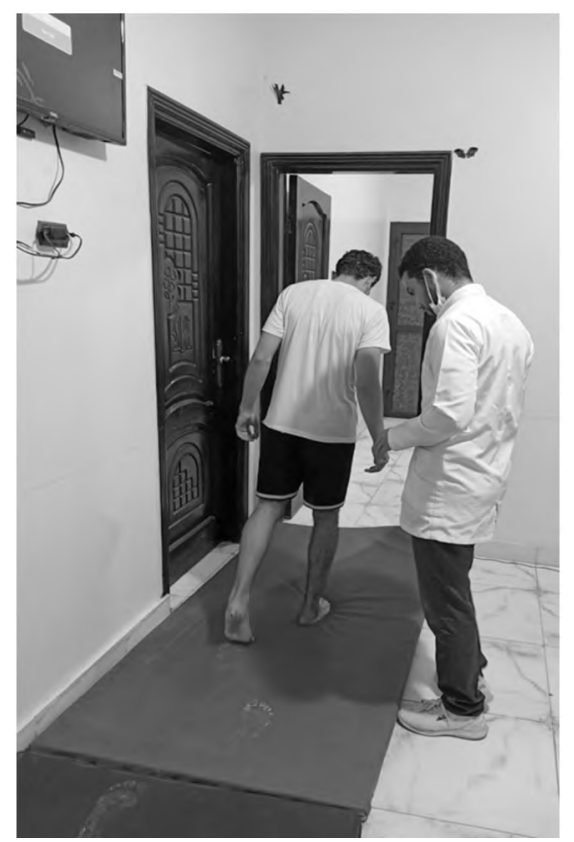

Fig. (1): Patient walk to take his foot prints.

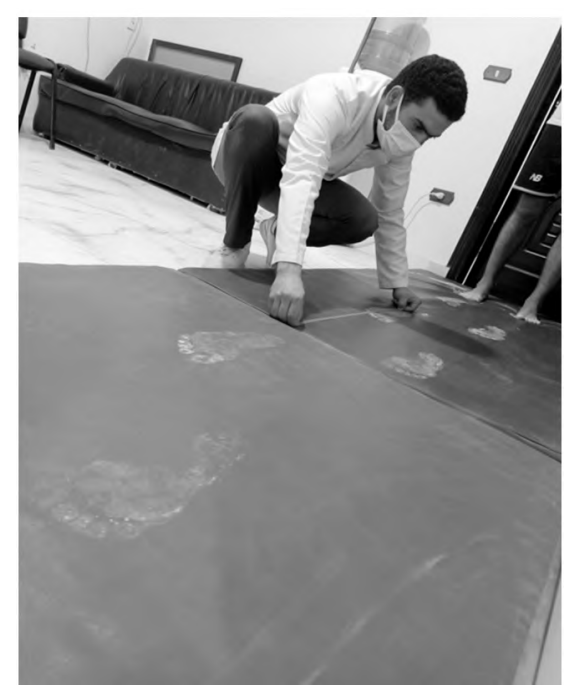

Fig. (2): Measuring gait parameters from foot prints.

\section{Therapist's position:}

The therapist was standing beside the side to be treated facing the patient.

\section{Hand placement:}

The therapist hand was placed on the lower end of femur bone of the affected side.

\section{Technique:}

The patient's flexed knee was placed over the therapist's shoulder while the popliteal fossa of the affected knee rested on the therapist shoulder. Then the patient was asked to push the therapist shoulder with his leg then voluntary relax. At this point of relaxation, the therapist pushed the bent knee up as far as possible in the direction of the shoulder on the same side of the affected leg without making the patient feel pain. This stretch maneuver was sustained for 5-10 seconds and then relaxed if the pain or restriction eased; the hip was taken into further flexion. It was ensured that there was no pain during the procedure. If the patient was felt pain the direction of the leg raise was altered by medial rotating or abducting the hip. The contra lateral leg was kept relaxed and allowed to move as it goes. At the end of the range, the position was held for 10 seconds and limb brought back to neutral position [16] Fig. (3).

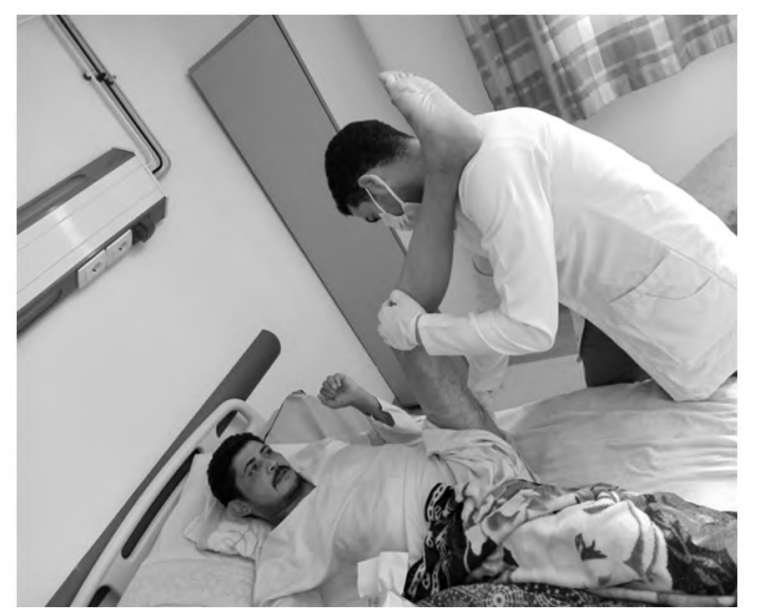

Fig. (3): Mulligan bent leg raise technique.

\section{Group B:}

This group received the traditional physical therapy program in the form of (active knee range of motion exercise and self-stretching of hamstring) five times a week for two months of treatment.

\section{1- Active range of motion exercises for knee joint:}

This type of exercises was performed in the following manner:

a- Leg lifts: Patients were asked to raise their leg so that their feet were 6 to 12 inches ( 15 to 31 centimeters) off the bed. Holding in air for a few seconds. Then return their legs to the bed.

b- Hip and knee bends: Patients were asked to point their toes up, slowly bend their knees up as close to their chest as possible. Straighten their legs and return to a flat position on the bed.

\section{2- Self-stretching of the hamstring muscles:}

Patients were asked to lay the affected leg along on a pillow while the other leg was straight with the foot resting on the bed. Then asked to bend forward at the hip, keeping the spine straight. With trying to push their legs down as straight as possible. Holding for 30 seconds then relax in an attempt to start the following same type of exercise [17] 


\section{Data analysis:}

In this study, the descriptive statistics (the mean and the standard deviation) were calculated for all subjects in both groups of the study to determine the homogeneity of the groups.

Unpaired $t$-test was conducted for comparison of the mean age between groups. ANOVA with repeated measures was conducted for comparison of Knee ROM and gait parameters between pretreatment, post I, post II and post III in each group and unpaired $t$ test for comparison between groups. The level of significance for all statistical tests was set at $p<0.05$. All statistical analysis was conducted through the statistical package for social studies (SPSS) version 25 for windows (IBM SPSS, Chicago, IL, USA).

\section{Results}

\section{Subject demographic data:}

Thirty male patients with hamstring shortening following lower limb burn participated in this study. The mean \pm SD age of the study group was $39.26 \pm 6.49$ years, with maximum value of 50 years and minimum value of 30 years. The mean \pm SD age of the control group was $40.6 \pm 6.89$ years, with maximum value of 50 years and minimum value of 31 years. There was no significance difference between both groups in the mean age values ( $p=$ $0.59)$.

\section{Effect of treatment on Knee ROM and gait parameters:}

\section{Between group comparison:}

There was no significant difference in knee ROM and gait parameters between the study and control groups at pre treatment $(p>0.05)$. There was a significant decrease in knee ROM and step width and a significant increase in step length and stride length of the study group at post I, post II and post III compared with that of the control group $(p<0.001)$. (Table 1).

Table (1): Mean knee flexion ROM, step length, stride length and step width at day pre- treatment, post I, post II and post III of the study and control groups.

\begin{tabular}{|c|c|c|c|c|}
\hline & $\begin{array}{c}\text { Pre treatment } \\
\text { Mean } \pm \text { SD }\end{array}$ & $\begin{array}{c}\text { Post I } \\
\text { Mean } \pm \text { SD }\end{array}$ & $\begin{array}{c}\text { Post II } \\
\text { Mean } \pm \text { SD }\end{array}$ & $\begin{array}{c}\text { Post III } \\
\text { Mean } \pm \text { SD }\end{array}$ \\
\hline & & Knee ROM (degrees) & & \\
\hline Study group & $25.33 \pm 1.48$ & $20.61 \pm 5.52$ & $11.46 \pm 1.27$ & $2.9 \pm 0.73$ \\
\hline Control group & $24.36 \pm 2.48$ & $24.35 \pm 3.22$ & $20.23 \pm 1.47$ & $14.13 \pm 1.45$ \\
\hline MD & 0.97 & -3.74 & -8.77 & -11.23 \\
\hline$t$-value & 1.29 & -2.26 & -17.42 & -26.64 \\
\hline \multirow[t]{2}{*}{$p$-value } & $0.2^{*}$ & $0.03 * *$ & $0.001 * *$ & $0.001 * *$ \\
\hline & & Step length $(\mathrm{cm})$ & & \\
\hline Study group & $12.28 \pm 1.1$ & $27.08 \pm 1.48$ & $37.77 \pm 1.77$ & $41.67 \pm 1.51$ \\
\hline Control group & $12.18 \pm 1.38$ & $13.69 \pm 1.29$ & $17.08 \pm 1.35$ & $20 \pm 1.2$ \\
\hline MD & 0.1 & 13.39 & 20.69 & 21.67 \\
\hline$t$-value & 0.21 & 26.27 & 35.88 & 43.3 \\
\hline \multirow[t]{2}{*}{$p$-value } & $0.82 *$ & $0.001 * *$ & $0.001 * *$ & $0.001 * *$ \\
\hline & & Stride length $(\mathrm{cm})$ & & \\
\hline Study group & $24.27 \pm 2.51$ & $40.58 \pm 1.84$ & $54.39 \pm 2.94$ & $75.78 \pm 4.01$ \\
\hline Control group & $25.2 \pm 2.61$ & $30.31 \pm 2.37$ & $34.56 \pm 2.44$ & $40.6 \pm 2.11$ \\
\hline MD & -0.99 & 10.27 & 19.83 & 35.18 \\
\hline$t$-value & 0.21 & 13.24 & 20.08 & 30.05 \\
\hline \multirow[t]{2}{*}{$p$-value } & $0.32 *$ & $0.001 * *$ & $0.001 * *$ & $0.001 * *$ \\
\hline & & Step width $(\mathrm{cm})$ & & \\
\hline Study group & $36.05 \pm 2.78$ & $27.96 \pm 1.63$ & $25.26 \pm 2.06$ & $16.98 \pm 0.82$ \\
\hline Control group & $37.44 \pm 3.53$ & $34.8 \pm 3.53$ & $32.46 \pm 3.19$ & $30.6 \pm 2.57$ \\
\hline $\mathrm{MD}$ & -1.39 & -6.84 & -7.2 & -13.62 \\
\hline$t$-value & -1.19 & -6.8 & -7.32 & -19.48 \\
\hline$p$-value & $0.24 *$ & $0.001 * *$ & $0.001 * *$ & $0.001 * *$ \\
\hline
\end{tabular}




\section{Within group comparison:}

There was a significant decrease in knee ROM and step width and a significant increase in step length and stride length in the study group at post I, post II and Post III compared with pre treatment $(p<0.05)$, a significant decrease in knee flexion
ROM and step width and a significant increase in step length and stride length at post II and III compared with post I $(p<0.001)$ and a significant decrease in knee ROM and step width and a significant increase in step length and stride length at post III compared with post II $(p<0.001)$. (Table 2$)$.

Table (2): Comparison of knee flexion ROM, step length, stride length and step width between pre-treatment, post I, post II and post III with in the study group.

\begin{tabular}{|c|c|c|c|c|c|c|c|c|c|c|c|c|}
\hline & \multicolumn{3}{|c|}{ Knee ROM } & \multicolumn{3}{|c|}{ Step length } & \multicolumn{3}{|c|}{ Stride length } & \multicolumn{3}{|c|}{ Step width } \\
\hline & MD & $\begin{array}{c}\% \text { of } \\
\text { change }\end{array}$ & $p$-value & MD & $\begin{array}{c}\% \text { of } \\
\text { change }\end{array}$ & $p$-value & MD & $\begin{array}{c}\% \text { of } \\
\text { change }\end{array}$ & $p$-value & MD & $\begin{array}{c}\% \text { of } \\
\text { change }\end{array}$ & $p$-value \\
\hline $\begin{array}{l}\text { Pre treatment- } \\
\text { Post I }\end{array}$ & 4.72 & 18.63 & $0.03 * *$ & -14.8 & 120.52 & $0.001 * *$ & -16.31 & 67.20 & $0.001 * *$ & 8.09 & 22.44 & $0.001 * *$ \\
\hline $\begin{array}{l}\text { Pre treatment- } \\
\text { Post II }\end{array}$ & 13.87 & 54.76 & $0.001 * *$ & -25.49 & 207.57 & $0.001 * *$ & -30.12 & 124.10 & $0.001 * *$ & 10.79 & 29.93 & $0.001 * *$ \\
\hline $\begin{array}{l}\text { Pre treatment- } \\
\text { Post III }\end{array}$ & 22.43 & 88.55 & $0.001 * *$ & -29.39 & 239.33 & $0.001 * *$ & -51.51 & 212.24 & $0.001 * *$ & 19.07 & 52.9 & $0.001 * *$ \\
\hline Post I-Post II & 9.15 & 44.40 & $0.001 * *$ & -10.69 & 39.48 & $0.001 * *$ & -13.81 & 34.03 & $0.001 * *$ & 2.7 & 9.66 & $0.001 * *$ \\
\hline Post I-Post III & 17.71 & 85.93 & $0.001 * *$ & -14.59 & 53.88 & $0.001 * *$ & -35.2 & 86.74 & $0.001 * *$ & 10.98 & 39.27 & $0.001 * *$ \\
\hline Post II-Post III & 8.56 & 74.69 & $0.001 * *$ & -3.9 & 10.33 & $0.001 * *$ & -21.39 & 39.33 & $0.001 * *$ & 8.28 & 32.78 & $0.001 * *$ \\
\hline
\end{tabular}

SD: Standard deviation. MD: Mean difference. $\quad$-value: Level of significance. *: Non- significant. **: Significant.

There was a significant decrease in step width and a significant increase in step length and stride length in the control group at post I, post II and post III compared with pre treatment $(p<0.001)$ while there was no significant difference in knee ROM between pre treatment and post I ( $p>0.05)$ and a significant decrease in knee ROM at post II and post III compared with pre treatment $(p<0.001)$.
There was a significant decrease in knee ROM and step width and a significant increase in step length and stride length at post II and III compared with post I $(p<0.01)$ and a significant decrease in step width and a significant increase in step length and stride length at post III compared with post II $(p<0.01)$. (Table 3).

Table (3): Comparison of knee flexion ROM, step length, stride length and step width between pre treatment, post I, post II and post III with in the control group.

\begin{tabular}{|c|c|c|c|c|c|c|c|c|c|c|c|c|}
\hline & \multicolumn{3}{|c|}{ Knee ROM } & \multicolumn{3}{|c|}{ Step length } & \multicolumn{3}{|c|}{ Stride length } & \multicolumn{3}{|c|}{ Step width } \\
\hline & MD & $\begin{array}{c}\% \text { of } \\
\text { change }\end{array}$ & $p$-value & MD & $\begin{array}{c}\% \text { of } \\
\text { change }\end{array}$ & $p$-value & MD & $\begin{array}{c}\% \text { of } \\
\text { change }\end{array}$ & $p$-value & MD & $\begin{array}{c}\% \text { of } \\
\text { change }\end{array}$ & $p$-value \\
\hline $\begin{array}{l}\text { Pre treatment- } \\
\text { Post I }\end{array}$ & 0.01 & 0.04 & $1 *$ & -1.51 & 12.4 & $0.001 * *$ & -5.11 & 20.28 & $0.001 * *$ & 2.64 & 7.05 & $0.001 * *$ \\
\hline $\begin{array}{l}\text { Pre treatment- } \\
\text { Post II }\end{array}$ & 4.13 & 16.95 & $0.001 * *$ & -4.9 & 40.23 & $0.001 * *$ & -9.36 & 37.14 & $0.001 * *$ & 4.98 & 13.3 & $0.001 * *$ \\
\hline $\begin{array}{l}\text { Pre treatment- } \\
\text { Post III }\end{array}$ & 10.23 & 42.00 & $0.001 * *$ & -7.82 & 64.2 & $0.001 * *$ & -15.4 & 61.11 & $0.001 * *$ & 6.84 & 18.27 & $0.001 * *$ \\
\hline Post I-Post II & 4.12 & 16.92 & $0.003 * *$ & -3.39 & 24.76 & $0.001 * *$ & -4.25 & 14.02 & $0.001 * *$ & 2.34 & 6.72 & $0.001 * *$ \\
\hline Post I-Post III & 10.22 & 41.97 & $0.001 * *$ & -6.31 & 46.09 & $0.001 * *$ & -10.29 & 33.95 & $0.001 * *$ & 4.2 & 12.07 & $0.001 * *$ \\
\hline Post II-Post III & 6.1 & 30.15 & $0.001 * *$ & -2.92 & 17.1 & $0.001 * *$ & -6.04 & 17.48 & $0.001 * *$ & 1.86 & 5.73 & $0.006^{* *}$ \\
\hline
\end{tabular}

SD: Standard deviation. MD: Mean difference. $\quad p$-value: Level of significance. *: Non- significant. **: Significant. 


\section{Discussion}

This study was designed to evaluate the effect of Mulligan Bent Leg Raise Technique on hamstring shortening with patients post burn and its effects on gait parameters and knee flexion ROM.

Burned patients exhibit poor muscle performance and reduced quality of life as a result of the musculoskeletal complications associated with burn and prolonged bed rest. A review of literature indicated that regular stretching exercises can reduce the musculoskeletal complications associated with burn by lengthening the muscle thus improving related joint range of motion, in turn, this increases functional capacity and enhances quality of life in patients [18]

Post-burn knee flexion contractures cause functional limitations of all lower extremity, not allowing the patient to walk normally, creating serious cosmetic defects, and, therefore, requiring surgical reconstruction. The anatomic features of knee flexion contractures and their treatment have been covered in literature far less than large joints of the upper extremities, and their treatment is still a challenge for many surgeons [19].

Regular stretching is an important part of rehabilitation of Post burn patients. The influence of it on flexibility, physical exercise capacity, and muscle length. The diminishing of disuse atrophy, catabolic effect and muscle contracture is expected. Also, side effects of stretching are very rare [20]

There are many several studies, trials and past literatures have been performed regarding the effects of stretching exercises in post burn patients, it has been suggested that stretching exercises could improve muscle flexibility, improves range of motion and decrease effects of disuse atrophy and probably lowers inflammation and improve quality of life [21].

The result of our study agreed with Komal et al., [22] that Mulligans bent leg raise technique showed more improvement in lowering the pain level and improved knee extension movement, participants functional activities and improving hamstring muscle flexibility.

Also our findings supported by the study of Varsha and Priti [23] while as the subjects in Mulligan BLR group have shown statistically significant improvement in their hamstrings flexibility with 6 days intervention and concluded that Mulligan Bent Leg Raise BLR technique had better efficacy than proprioceptive neuromuscular facil- itation (PNF) agonist contraction in improving hamstrings flexibility.

In a study carried out by Jupudi et al., [24], Mulligan's Bent leg raise(BLR) was found to be significantly more effective than passive stretching in healthy females with hamstrings tightness which is similar to the results of our study.

Also, Stathopoulos et al., [25] have concluded that the result of Mulligan's mobilization with movement technique has an immediate positive effect on both range of motion and pain in subjects with painful limitation of movement.

Also our finding supported by Pavithra [26] have said that there are an increasing number of reports espousing the clinically beneficial effect of Mulligan's mobilization with movement techniques. The most frequent report effect is that of an immediate and substantial pain reduction accompanied by improved function.

Khuman et al., [27] stated Mulligan BLR has biomechanical effects on pelvis movements, on lumbosacral neural structures also apart from hamstrings muscle. The BLR technique works on the neural tissue component and also on the low back leading to increased flexibility. Pelvic positioning in Mulligan BLR has an effect on hamstrings length. These may be the probable reasons for better efficacy of BLR in improving extensibility of hamstrings muscle.

In contrary, Studies carried out by Patni et al., [28], Hing et al., [29] and Beyerlein et al., [30] stated that improvement by the BLR technique, might be due to mobilization of the painful, sensitized, nerve tissues, similar to the "slider" effects and concluded that hamstring flexibility gains obtained from a single bout of both passive stretching and BLR were almost similar and difference between the two interventions were negligible and there were no immediate improvement observed.

Finally, from the previous discussion of these results and according to reports of other investigators in similar studies, It can be explained that Mulligan bent leg raise technique (BLR) is effective in improving the hamstring muscle flexibility in individuals with hamstring muscle tightness as evidenced by the highly significant improvement in knee extension ROM and gait parameters. The results of the current study would introduce a scientific applicable protocol to help physical therapists, surgeons in their dealing with hamstring shortening and limitations occurs after burn, organize a plan of care to overcome this problem 
and prevent the progression of pain and the development of associated morbidities including frozen knee and improve the quality of life of those patients.

This study was limited by small sample size and low number of assessment methods for those patients who complain of shortening of hamstring muscles following lower limb burn.

Conducting more similar studies using other types of therapeutic modalities and training programs for a longer period of time and increasing the number of patients in addition to comparing them with the results of the current study to obtain better statistical results to reach the best methods of treatment for patients with hamstring shortening following lower limb burn. Furthermore, additional studies are needed to determine the effect of hamstring flexibility on the psychological conditions and the quality of life for lower limb burn patients.

These significant improvements in walking characteristics and goniometric data were attributed to the immobilization of muscles in a lengthened, position (that was associated with the increased number of sarcomeres in series, and the increased muscles length) and due to the optimal plastic deformation of the tissue from the prolonged low force mechanical stretch, indicating that there was a direct correlation between the stretch duration and the resulted proportion of the plastic permanent elongation [19]

\section{Conclusion:}

This study concludes that Mulligan bent leg raise technique (BLR) is effective in improving the hamstring muscle flexibility in individuals with hamstring muscle tightness as evidenced by the highly significant improvement in knee ROM and gait parameters. The results of the current study would introduce a scientific applicable protocol to help physical therapists, surgeons in their dealing with hamstring shortening and limitations occurs after burn, organize a plan of care to overcome this problem and prevent the progression of pain and the development of associated morbidities including frozen knee and improve the quality of life of those patients.

\section{References}

1- RICHARD R.L. and STALEYS M.J.: Burn Care and Rehabilitation, Principle and Practice 1 st (ed.), F.A. Davis Company, Ch. 11, pp. 267, 300, 1994.

2- RICHARD R.L. and STALEY M.J.: Burn Patient Evaluation and Treatment Planning. In Richard R.L., Staley M.J., Editors. Burn Care and Rehabilitation: Principle and Practice Philadelphia F.A. Davis, 201-220, 1994.
3- RICHARD R.L., STALEY M.J., and FINLEY R.K.: The Evaluation of Burn Rehabili-tation Management. In Richard R.L. and Staley M.J., (Eds.), Burn Care and Rehabilitation: Principle and Practice Phyladelphia F.A. Davis. Ch (1), pp. 4, 1994.

4- SILVERBERG R., LOMBARDO G., GORGA D., NAGLER W., HIMEL H. and YURT R.: Gait Variables of Patients after Lower Extremity Burn Injuries J. Burn. Care. Rehabil., 21 (3): 259-267. 2000.

5- SILVERSTEIN L.S., FARRETT W.D., MAURER B.T. and HILLSTROM H.J.: Gait Analysis and Bivalved Serial Casting of an Athlete with Shortened Gastrocnemuis Muscles: A Single Case Design J. Orthop. Phys. Ther., 25 (4): 282-288, 1997.

6- PATNI O., SARAVANAN M., SHAIKH A., JUNEJA A. and SHAIKH N.: Effect of single bout of passive stretching and mulligan's bent leg raise (BLR) on hamstring flexibility in young adults with asymptomatic bilateral hamstring tightness. J. Dent Med. Sci., 9: 13-17, 2013.

7- PHANSOPKAR P.A. and KAGE V.: Effects of mulligan's two leg rotation technique in hamstring flexibility: Prepost experimental study. Rom. J. Phy. Ther., 20: 28-33. 2014.

8- MOWAFY M.E., NOSSIER A.A., ABD EL GHANY S. and ABD EL BAKY A.M.: Gastrocnemius-Soleus Mechanical Stretch in Relation to Gait in Lower Limb Burn. The Egyptian Journal of Hospital Medicine, 6 (1): 37-44, 2002.

9- DUNCAN C.E.: A Gait Training Suggestion for Lengthening Gastrocnemius- Soleus Muscles. Phjys. Ther., 69 (9): 773-776, 1989.

10- ELSHERBINY O.E., EL FAHAR M.H., WEHEIDA S.M., SHEBL A.M. and SHRIEF W.I.: Effect of burn rehabilitation program on improving quality of life (QoL) for hand burns patients: A randomized controlled study. European Journal of Plastic Surgery, 41(4): 451-458, 2018.

11- KAWILARANG B.: Functional Reconstruction of PostBurn Hand Contractures. Int. J. Med. Rev. Case Rep., 3 (12): 873-878, 2019.

12- NOSSIER A.A.: Efficiency - Assessment of Selected Gait Parameters in Some Musculo-skeletal Disorders. UN Published Master Thesis, Cairo University, 1985.

13- OMAR M.T., ABD EL BAKY A.M. and EBID A.A. Lower-limb muscular strength, balance, and mobility levels in adults following severe thermal burn injuries. Journal of Burn Care \& Research, 38 (5): 327-333, 2017.

14- GRISHKEVICH V.M. and VISHNEVSKY A.V.: Postburn knee flexions contractures: Anatomy and methods of their treatment. Tropical Medicine \& Surgery, 2013.

15- HALE A., O'DONOVAN R., DISKIN S., MCEVOY S., KEOHANE C. and GORMLEY G.: Physiotherapy in burns, plastics and reconstructive surgery. Impairment and Disability Course University of Limerick. Irlandia: The Educational Company of Ireland, 2-26, 2013.

16- KAGE V. and RATNAM R.: Immediate effect of active release technique versus mulligan bent leg raise in subjects with hamstring tightness: A randomized clinical trial. Int. J. Physiother Res., 2 (1): 301-304, 2014. 
17- CHEN H.M., WANG H.H., CHEN C.H. and HU H.M.: Effectiveness of a stretching exercise program on low back pain and exercise self-efficacy among nurses in Taiwan: A randomized clinical trial. Pain Management Nursing, 15 (1): 283-291, 2014.

18- MARZUCA-NASSR G.N., SANMARTÍN-CALÍSTO Y., GUERRA-VEGA P., ARTIGAS-ARIAS M., ALEGRÍA A. and CURI R.: Skeletal muscle aging atrophy: Assessment and exercise-based treatment. Reviews on New Drug Targets in Age-Related Disorders, 123-158, 2020.

19- RICHARD R., SHANESY C.P. and MILLER S.F.: Dynamic Versus Statis Splints: A Prospective Case for Sustained Stress J. Burn Care. Rehabil., 16 (3): 284-287, 1995.

20- LYONS M.M. : Low -Load, Prolonged Stretch in Treatment of Elbow Flexion Contractures Secondary to Head Trauma: A Case Report. Phys. Ther., 69 (4): 292-296, 1989.

21- MEYER III, W.J., MARTYN J.J., WIECHMAN S., THOMAS C.R. and WOODSON L.: Management of pain and other discomforts in burned patients. In Total burn care, (pp. 679-699). Elsevier, 2018.

22- KAGE V. and RATNAM R.: Immediate effect of active release technique versus mulligan bent leg raise in subjects with hamstring tightness: A randomized clinical trial. Int. J. Physiother Res., 2 (1): 301-304, 2014.

23- GAJDOSIK R.L. and BOHANNON R.W.: Clinical Measurement Range of Motion. Review of goniometry Emphasizing Reliability and Validity. Phys. Ther., 67 (12): 18671872, 1987.

24- JUPUDI M., KUMAR S. and MOHAN L.: Effects of Mulligan's Mobilization Adjunct to Agility and Perturbation Exercises in Subjects with Knee Osteoarthritis.
International Journal for Advance Research and Development, 2 (11): 58-64, 2017.

25- STATHOPOULOS N., DIMITRIADIS Z. and KOUMANTAKIS G.A.: Effectiveness of Mulligan's mobilization with movement techniques on range of motion in peripheral joint pathologies: A systematic review with metaanalysis between 2008 and 2018. Journal of manipulative and physiological therapeutics, 42 (6): 439-449, 2019.

26- PAVITHRA K.: A Comparative study on the Effectiveness of Mulligan Technique and Stabilization Exercise on Pain and Neck Disability among Nonspecific Mechanical Neck Pain Patients (Doctoral dissertation, RVS College of Physiotherapy, Coimbatore), 2019.

27- KHUMAN P.R., SURBALA L., PATEL P. and CHAVDA D.: Immediate Effects of Single Session Post Isometric Relaxation Muscle Energy Technique Versus Mulligan's Bent Leg Raise Technique on Pain and Hamstring Flexibility in Knee Osteoarthritis Participants: A Randomised Controlled Study. Physiotherapy, 3 (9): 324-335, 2014.

28- PATNI O., SHAIKH A. and PATEL R.: Effect of single bout of passive stretching and Mulligan's Bent Leg Raise (BLR) on Hamstring flexibility in young adults with asymptomatic bilateral Hamstring tightness. Dental and Medical Sciences, 9 (3): 12, 2013.

29- HING W., HALL T., RIVETT D. A., VICENZINO B. and MULLIGAN B.: The Mulligan Concept of Manual Therapy-eBook: Textbook of Techniques. Elsevier Health Sciences, 2015.

30- BEYERLEIN C.: Le concept Mulligan: Preuves cliniques et formation. Kinésithérapie, la revue, 8 (82): 27-31, 2008. 


\section{تأثير تقنية موليجان لرفع الساق

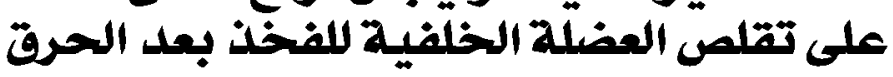

$$
\text { الخلفية: يمر مرضى حرق الطرف السفلى بصعوبة فى بسط وثنى الركبة ومن ثم صعوبة فى المشى. }
$$

الهدف: تصديد تأثير تقنية موليجان لرفع الساق على إطالة العضلة الخلفية للفذذ وتصسين حركة مفصل الركبة فى مدى البسط والثنى بعد

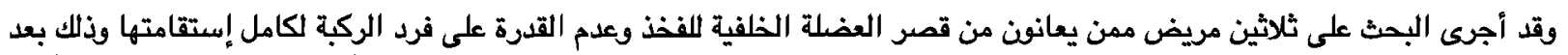

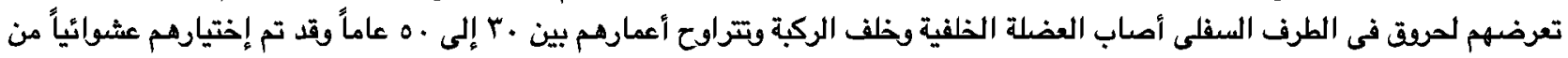

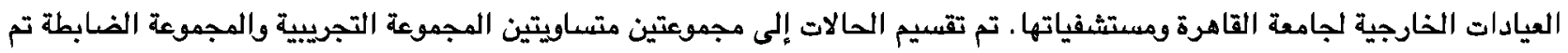

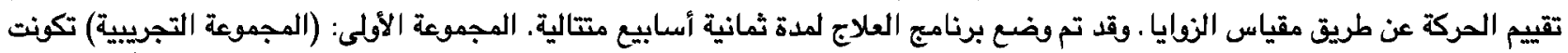

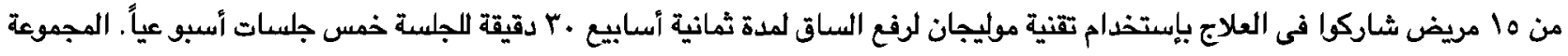

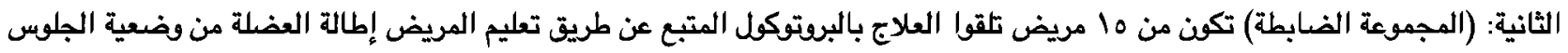

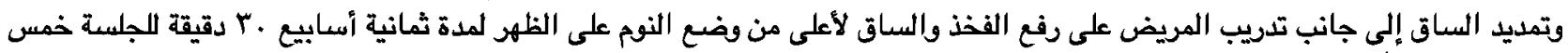
جلسات أسبوعياً بالإضافة إلى العلاج الدرئي العرئى

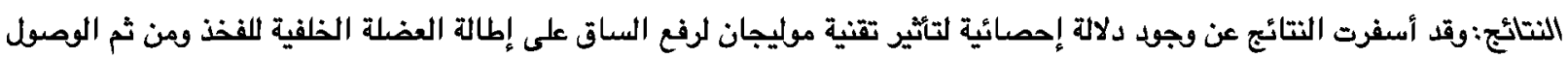

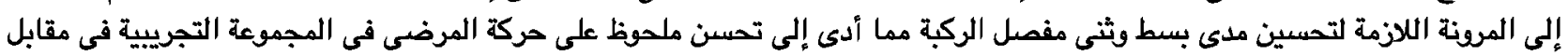
المجموعة الضـابطة.

الخلاصة: من هذه النتائج يمكن الإستدلال أن تقنية موليجان لرفع الساق لها تأثير مباشر فى إطالة العضلة الخلفية الفخذ وزيادة مدى

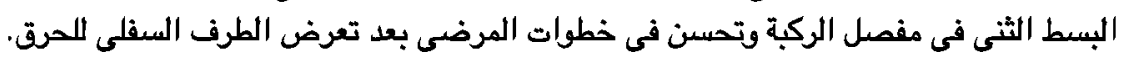

